\title{
Two-Component Catalytic Systems Based on Platinum(II) and Platinum(0) Complexes for Hydrosilylation of Polysiloxanes
}

\author{
R. M. Islamova ${ }^{a}$, A. V. $\operatorname{Vlasov}^{a}$, M. V. Dobrynin ${ }^{a}$, E. A. Masloborodova ${ }^{b}$, and E. V. Kaganova ${ }^{b}$ \\ ${ }^{a}$ St. Petersburg State University, Universitetskaya nab. 7-9, St. Petersburg, 199034 Russia \\ e-mail:r.islamova@spbu.ru \\ ${ }^{b}$ Lebedev Scientific Research Institute of Synthetic Rubber, St. Petersburg, Russia
}

Received August 3, 2015

\begin{abstract}
The effect of the binary catalytic systems [the Karstedt catalyst-platinum(II) isocyanide complex] of the cure of vinyl-containing polydimethylsiloxane and hydride-containing siloxane oligomer via the hydrosilylation reaction has been studied.
\end{abstract}

Keywords: hydrosilylation, curing, polysiloxane, the Karstedt catalyst, platinum(II) isocyanide complex, catalytic system

DOI: $10.1134 / \mathrm{S} 1070363215110171$

Hydrosilylation of olefins is a clue reaction in preparation of industrially important organosilicon compounds. Catalytic hydrosilylation as a route to the siloxane rubbers curing is of special practical importance; the so produced cross-linked derivatives exhibit a range of utilitarian properties including heat and cold resistivity, good electrical insulation properties, stability towards irradiation, oil resistance upon heating, chemical and biological inertness, environmental safety, etc. The mentioned reaction is based on the catalyzed interaction of vinyl-containing polysiloxanes with hydride-containing siloxane oligomers or polymers to form the polymer network (Scheme 1) [1-4]. The addition usually proceeds against the Markovnikov rule.
Transition metal compounds (and especially platinum complexes) serve as catalysts of the siloxanes curing via the hydrosilylation reaction [2-4].

Since the discovery of the Karstedt catalyst [vinylsiloxane complex of platinum(0) (1)] the range of potential catalysts of the hydrosilylation has been significantly extended (majorly for the reactions of low-molecular olefins); nevertheless, complex $\mathbf{1}$ has remained the most widely used industrial catalyst $[2,4]$. However, the Karstedt catalyst exhibits high activity even at room temperature, resulting to in the poor selectivity of the process and, in certain cases, deteriorating the products properties [5] (Scheme 2).

Scheme 1.

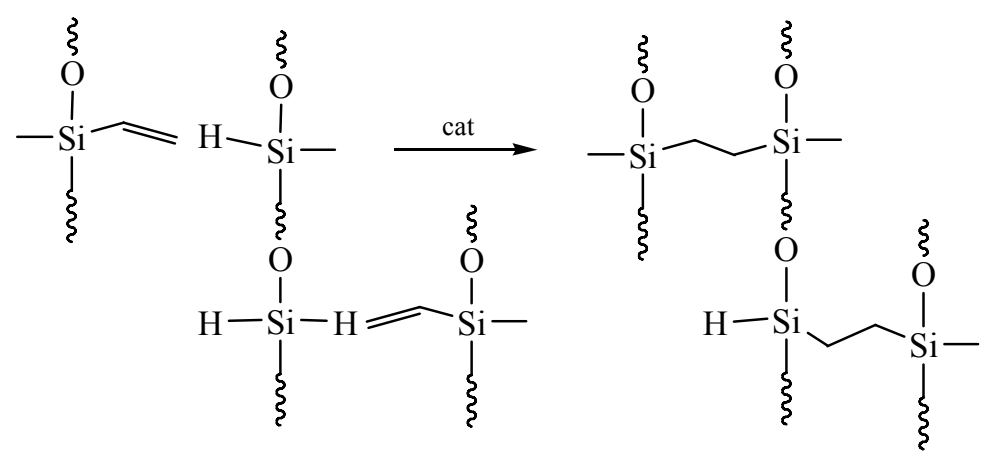




\section{Scheme 2.}

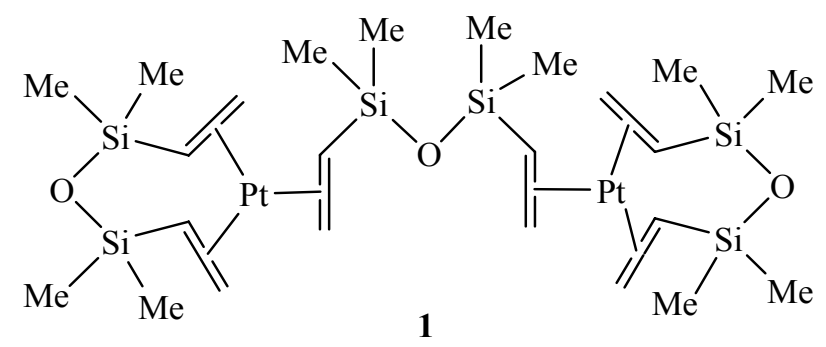

Curing of polysiloxanes can be catalyzed by certain platinum(II) complexes possessing high stability upon incubation, for example, the Lamoreaux catalyst, phosphine-acetylide platinum(II) complexes, etc. [3, 6-10]. However, most of the suggested alternative catalysts are active only at the elevated temperature but are not efficient in the "cold" (room-temperature) curing. For instance, isocyanide complexes of platinum(II) catalyze polysilixanes curing only upon heating above $70^{\circ} \mathrm{C}$ [9].

In view of this, the hydrosilylation reactions are often catalyzed by the Karstedt catalyst in combination with various inhibitors in order to deteriorate its activity. This allows for better control of the reaction and preparation of the cured product with improved properties. Various unsaturated compounds acting as platinum(0) ligands (nitriles, sulfoxides, alcohols, phosphines, phosphates, ketones, hydroperoxides, etc.) serve as the inhibitors [2,4]. The inhibition evidently proceeds as the Karstedt catalyst conversion into the less active form due to the equilibrium ligand exchange (Scheme 3).

The sufficient lability of the formed complex is important. For example, application of organic isocyanides as additives leads to too strong inhibition, and the catalyst loses its activity at room temperature $[2,9$, 10]. Likely, this is due to the strong binding of the isocyanide ligand at the metal center [11].

We have suggested application of the inhibiting additives of transition metals complexes as a novel approach to inhibit the high activity of the Karstedt catalyst. In this work we investigated the hydrosilylation in the presence of the two-component catalytic systems containing the Karstedt catalyst (1) and bis(isocyanide) complex of platinum dichloride (2 or 3). The interaction of polydimethylsiloxane containing terminal vinyl groups (4) and hydridecontaining siloxane oligomer (5) (Scheme 4) was used as a model reaction.

We considered the following main parameters of the reaction: the time required for two-fold increase of the reaction mixture viscosity ( $\left.\tau_{\text {pot-life }}\right)$ and the curing time $\left(\tau_{\text {curing }}\right)$. Those parameters of the curing in the presence of the Karstedt catalyst $\left(1.0 \times 10^{-5} \mathrm{~mol} / \mathrm{L}\right)$ at room temperature were of $3 \mathrm{~min}$ and $6 \mathrm{~h}$, respectively (see table). The low $\tau_{\text {pot-life }}$ value resulted in the premature curing, accompanied by formation of bubbles, cracks, and other defects in the formed material. On top of that, the lifetime period was too short to allow for addition of some filler in the curing system in order to improve the composition of the cured siloxane. Decrease of the Karstedt catalyst concentration was pointless, since the prepared cured product was of poor quality ("loose") despite the acceptable $\tau_{\text {pot-life }}$ and $\tau_{\text {curing }}$ values. Evidently, that was due to the low density of the formed polymer network resulting from the process nonequilibrium and the relatively slow diffusion of the catalyst.

Coinciding with the expectations based on the available data $[9,10]$, curing of compounds 4 and 5 via the hydrosilylation reaction in the presence of only catalyst 2 or $3\left(1.0 \times 10^{-3}-1.0 \times 10^{-5} \mathrm{~mol} / \mathrm{L}\right)$ at room temperature did not occur. At $100^{\circ} \mathrm{C}$ and in the studied catalyst concentration range the $\tau_{\text {curing }}$ value was of $6 \mathrm{~h}$ to 1 day (see table). The cyclohexyl-containing compound 3 was somewhat more active towards the curing, likely due to the higher solubility in the reaction mixture.

The combined use of the Karstedt catalyst and the isocyanide complex $\mathbf{3}$ (strongly differing in the activity) for the curing (the catalysts ratio was of $1: 1$,

Scheme 3.

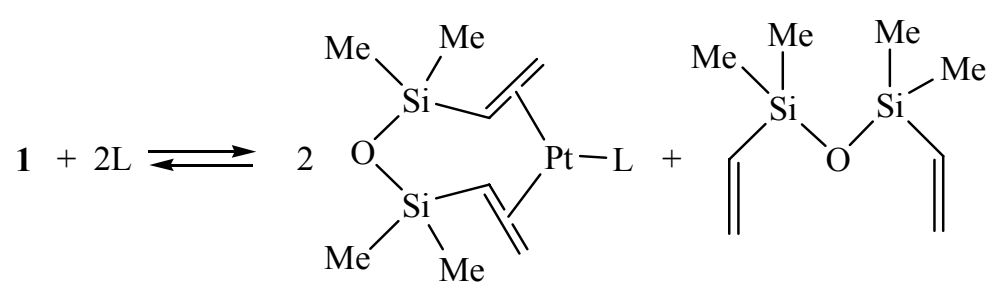

RUSSIAN JOURNAL OF GENERAL CHEMISTRY Vol. 85 No. 112015 
Scheme 4.
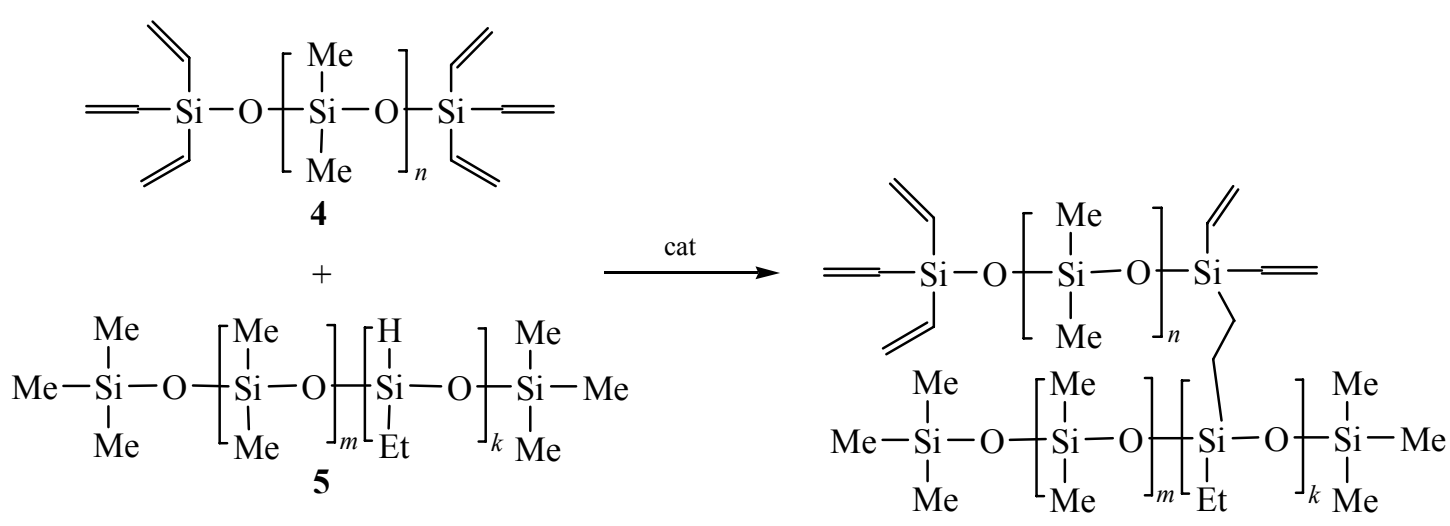

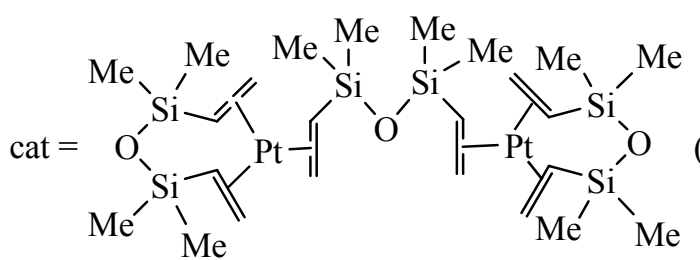

and the concentration of each of the components was of $1.0 \times 10^{-5} \mathrm{~mol} / \mathrm{L}$ ) gave the optimal values of $\tau_{\text {pot-life }}$ (35 $\mathrm{min})$ and $\tau_{\text {curing }}(21 \mathrm{~h}$ ) at room temperature. Using the proposed two-component system, we obtained transparent and structurally uniform cured siloxanes containing no obvious defects.

When the complex $\mathbf{2}$ was used instead of complex $\mathbf{3}$ in combination with the Karstedt catalyst $(1: 1)$, the catalytic system activity was slightly reduced at all the studied components concentrations (see table).

Using of the combined catalytic system allowed curing of compounds $\mathbf{4}$ and $\mathbf{5}$ upon heating as well; that was impossible using the Karstedt catalyst alone. The curing times at $100^{\circ} \mathrm{C}$ are collected in the table.

Increase of the concentration of the Karstedt catalyst in the combined system, concentration of the<smiles>Cc1cccc(C)c1N=CP(Cl)(Cl)=Nc1c(C)cccc1C</smiles>

(2),<smiles>ClP(Cl)(N=C1CCCCC1)=NC1CCCCC1</smiles>

complex 2 or 3 being constant, resulted in acceleration of the hydrosilylation reaction. On the contrary, increase of the concentration of the complex $\mathbf{2}$ or $\mathbf{3}$ decelerated the process, i.e., increased the $\tau_{\text {pot-life }}$ and $\tau_{\text {curing }}$ values (see table). That was due to the additive effect of the platinum complexes: the isocyanide complex acted as the inhibitor, and the Karstedt complex acted as the catalyst.

We believe that the controlled inhibition of the Karstedt catalyst with the isocyanide complexes of platinum(II) was due to the equilibrium reaction of the ligand exchange between the complexes occurring in the system (Scheme 5).

Likely, only the olefinic complex 1 exhibited the catalytic activity. Our data (see Table) as well as the earlier published results $[2,9,10]$ revealed the

Scheme 5.

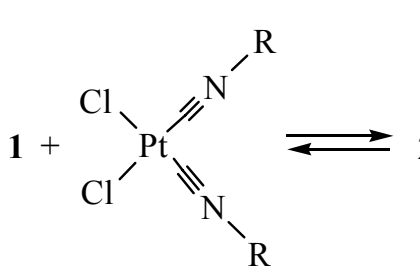

2, 3<smiles>C=C[Si](C)(C)O[Si](C)(C)C=CPC([NH+])[NH2+]</smiles>

6, 7<smiles>C[Si](C)(C)O[Si](C)(C)/C=C\P(Cl)(Cl)(Cl)Cl</smiles>

8 
ISLAMOVA et al.

The influence of platinum catalysts and catalytic systems on the curing of compounds $\mathbf{4}$ and $\mathbf{5}$ via hydrosilylation reaction

\begin{tabular}{|c|c|c|c|c|c|}
\hline Catalyst/catalytic system & $\begin{array}{c}\text { Concentration of } \\
\text { Karstedt catalyst } \\
\mathbf{1 , ~ m o l} / \mathrm{L}\end{array}$ & $\begin{array}{l}\text { Concentration of } \\
\text { isocyanide catalyst } \\
(2 \text { or } 3), \mathrm{mol} / \mathrm{L}\end{array}$ & $\begin{array}{l}\tau_{\text {pot-life }} \\
\text { at } 20^{\circ} \mathrm{C}, \\
\text { min }\end{array}$ & $\begin{array}{c}\tau_{\text {curing, }} \\
\text { at } 20^{\circ} \mathrm{C}\end{array}$ & $\begin{array}{c}\tau_{\text {curing }}, \\
\text { at } 100^{\circ} \mathrm{C}\end{array}$ \\
\hline \multirow[t]{3}{*}{1} & $1.0 \times 10^{-4}$ & - & 0.7 & $6 \mathrm{~min}$ & - \\
\hline & $1.0 \times 10^{-5}$ & - & 3 & $6 \mathrm{~h}$ & - \\
\hline & $1.0 \times 10^{-6}$ & - & 40 & $24 \mathrm{~h}$ & 15 \\
\hline \multirow[t]{3}{*}{2} & - & $1.0 \times 10^{-3}$ & - & - & $10 \mathrm{~h}$ \\
\hline & - & $1.0 \times 10^{-4}$ & - & - & $18 \mathrm{~h}$ \\
\hline & - & $1.0 \times 10^{-5}$ & - & - & $24 \mathrm{~h}$ \\
\hline \multirow[t]{3}{*}{3} & - & $1.0 \times 10^{-3}$ & - & - & $6 \mathrm{~h}$ \\
\hline & - & $1.0 \times 10^{-4}$ & - & - & $9 \mathrm{~h}$ \\
\hline & - & $1.0 \times 10^{-5}$ & - & - & $17 \mathrm{~h}$ \\
\hline \multirow{2}{*}{$\begin{array}{l}\text { 1-Dimethylphenylisocyanide } \\
\qquad(1: 1)\end{array}$} & $1.0 \times 10^{-3}$ & - & - & 7 days without curing & \\
\hline & $1.0 \times 10^{-4}$ & - & - & 7 days without curing & \\
\hline \multirow[t]{6}{*}{$1-2$} & $1.0 \times 10^{-4}$ & $1.0 \times 10^{-4}$ & 2 & $15 \mathrm{~min}$ & - \\
\hline & $1.0 \times 10^{-5}$ & $1.0 \times 10^{-5}$ & 140 & $24 \mathrm{~h}$ & $15 \mathrm{~min}$ \\
\hline & $2.0 \times 10^{-4}$ & $1.0 \times 10^{-4}$ & 1.4 & $10 \mathrm{~min}$ & - \\
\hline & $2.0 \times 10^{-5}$ & $1.0 \times 10^{-5}$ & 35 & $18 \mathrm{~h}$ & $12 \mathrm{~min}$ \\
\hline & $1.0 \times 10^{-4}$ & $2.0 \times 10^{-4}$ & 12 & $3 \mathrm{~h}$ & $5 \mathrm{~min}$ \\
\hline & $1.0 \times 10^{-5}$ & $2.0 \times 10^{-5}$ & - & 7 days without curing & $130 \mathrm{~min}$ \\
\hline \multirow[t]{7}{*}{ 1-3 } & $1.0 \times 10^{-4}$ & $1.0 \times 10^{-4}$ & 1 & $7 \mathrm{~min}$ & - \\
\hline & $5.0 \times 10^{-4}$ & $5.0 \times 10^{-4}$ & 4 & $12 \mathrm{~min}$ & - \\
\hline & $1.0 \times 10^{-5}$ & $1.0 \times 10^{-5}$ & 35 & $21 \mathrm{~h}$ & $13 \mathrm{~min}$ \\
\hline & $2.0 \times 10^{-4}$ & $1.0 \times 10^{-4}$ & 2 & $7 \mathrm{~min}$ & - \\
\hline & $2.0 \times 10^{-5}$ & $1.0 \times 10^{-5}$ & 10 & $5 \mathrm{~h}$ & $8 \mathrm{~min}$ \\
\hline & $1.0 \times 10^{-4}$ & $2.0 \times 10^{-4}$ & 6 & $1 \mathrm{~h}$ & $2 \mathrm{~min}$ \\
\hline & $1.0 \times 10^{-5}$ & $2.0 \times 10^{-5}$ & - & 7 days without curing & $70 \mathrm{~min}$ \\
\hline
\end{tabular}

complete inhibition of the Karstedt complex by addition of pure isocyanide, reflecting no catalytic activity of the formed complexes 6 and 7. The same could be concluded in the case of the platinum(II) complex 8 taking into account our experimental results and the reference data $[2,4]$.

The equilibrium shown in Scheme 5 should be noticeably shifted towards formation of the platinum (0) isocyanide complex (6 or 7): the isocyanide, being a $\pi$-accepting ligand, should be stronger bound at the metal center in the lower oxidation state, the latter showing the higher electronic density and being capable of the reverse $\pi$-doping [11]. Nevertheless, the equilibrium concentration of complex $\mathbf{1}$ in that system should be higher than in the case of the pure isocyanide as the inhibitor. That resulted in the weaker inhibiting of the Karstedt catalyst with the complexes 2 and 3 and enabled the fine tuning of the catalytic activity of the system.

To conclude, the proposed two-component system containing the Karstedt catalyst and the isocyanide complex of platinum(II) allowed for curing of the vinyl-containing polysiloxane and the hydridecontaining siloxane oligomer via the hydrosilylation reaction with the reasonable rate at room temperature as well as upon heating.

\section{EXPERIMENTAL}

Commercially available solution of the Karstedt catalyst $1(0.1 \mathrm{~mol} / \mathrm{L})$ in polydimethylsiloxane (Aldrich, USA) was used. 
The platinum(II) cis-bis(2-isocyano-1,3-dimethylbenzene)dichloride (2) and platinum(II) cis-bis(isocyanocyclohexane)dichloride complexes were prepared as described elsewhere [12].

Vinyl-terminated polydimethylsiloxane $(0.5 \mathrm{wt} \%$ of $\left.-\mathrm{CH}=\mathrm{CH}_{2}\right) \quad 4$ and the copolymer of dimethylsiloxane with ethylhydrosiloxane $(0.7 \mathrm{wt} \%$ of $\equiv \mathrm{Si}-\mathrm{H})$ 5 were prepared as described in [1]. Molecular parameters of the polymers (the mass-average $M_{\mathrm{w}}$ and the number-average $M_{\mathrm{n}}$ molecular masses) were determined via GPC method using a Waters GPC 2000 System liquid chromatograph (THF as eluent, the flow rate of $1.0 \mathrm{~mL} / \mathrm{min}$ ). $M_{\mathrm{w}}=80000, M_{\mathrm{n}}=33800$ (4) and $M_{\mathrm{w}}=8150, M_{\mathrm{n}}=4600(\mathbf{5})$.

Curing procedure. The required amount of the platinum catalyst/catalytic system $\left(1.0 \times 10^{-3}-1.0 \times\right.$ $10^{-6} \mathrm{~mol} / \mathrm{L}$ ) were dissolved in a minimum volume of $\mathrm{CH}_{2} \mathrm{Cl}_{2}(0.05-0.3 \mathrm{~mL})$ and added to polymer 4 specimen. The mixture was stirred and dried under reduced pressure at $30^{\circ} \mathrm{C}$ during a day. The so prepared formulation was added to a mixture of the hydride-containing siloxane oligomer $5(10 \mathrm{~g})$ and polymer $4(50 \mathrm{~g})$ in the $1: 1$ ratio. The curing was performed in aluminum plates or in glass Petri dished either at room temperature or upon heating $\left(100^{\circ} \mathrm{C}\right)$ in a thermostat.

The lifetime was determined as the time required for approximately two-fold increase of the reaction mixture viscosity. The curing time was determined as the time from the components mixing at the experiment temperature to the preparation of the cured product.

\section{ACKNOWLEDGMENTS}

This work was performed in the frame of
the Federal Target Program (agreement no. 14.576.21.0028, synthesis of the polymers 4 and 5) and was financially supported by the Russian Scientific Foundation (grant no. 14-43-00017, preparation of the complexes $\mathbf{2}$ and $\mathbf{3}$ and study of the catalytic activity).

\section{REFERENCES}

1. Shets, M., Silikonovyi kauchuk (Silicone Rubber), Leningrad: Khimiya, 1975.

2. Hydrosilylation: A Comprehensive Review on Recent Advances, Marciniec, B., Ed., Amsterdam: Springer, 2009, vol. 1.

3. Demakova, M.Ya., Bolotin, D.S., Bokach, N.A., Islamova, R.M., Starova, G.L., and Kukushkin, V.Yu., ChemPlusChem., 2015, vol. 80, no. 11, p. 1607. DOI: 10.1002/cplu201500327.

4. Troegel, D. and Stohrer, J., Coord. Chem. Rev., 2011, vol. 255, p. 1440. DOI: 10.1016/j.ccr.2010.12.025.

5. Gorshkov, A.V., Kauchuk I Rezina, 1989, no. 6, p. 36.

6. Lamoreaux, H.F., US Patent 3313773 (A), 1967.

7. Li, J., Peng J., Deng, Y., Ma, C., Zhang, G., Bai, Y., and Lai, G., Appl. Organomet. Chem., 2012, vol. 26, no. 9, p. 461. DOI: 10.1002/aoc.2881.

8. de Vekki, D.A., Ol'sheev, V.A., Spevak, V.N., and Skvortsov, N.K., Russ. J. Gen. Chem., 2001, vol. 71, no. 12 , p. 1912. DOI: 10.1023/A:1014292310639.

9. Kishi, K., Ishimaru, T., Ozono, M., Tomita, I., and Endo, T., Macromolecules, 1998, vol. 31, no. 26, p. 9392 . DOI: $10.1021 / \mathrm{ma} 981438$ a.

10. Kishi, K., Ishimaru, T., Ozono, M., Tomita, I., and Endo, T., Intern. J. Adhesion\&Adhesives, 2000, vol. 20, p. 253. DOI: 10.1016/S0143-7496(99)00050-0.

11. Isonitrile Chemistry, Ugi, I., Ed., New York: Academic Press, 1971.

12. Bonati, F. and Minghetti, G., J. Organomet. Chem., 1970, vol. 24, p. 251. 